\title{
Design of Teaching Aid System based on WeChat Public Platform
}

\author{
Kun Liu \\ Shandong Provincial Key \\ Laboratory of Network Based \\ Intelligent Computing \\ University of Jinan \\ Jinan, China \\ ise_liuk@ujn.edu.cn
}

\author{
Kun Ma \\ Shandong Provincial Key \\ Laboratory of Network Based \\ Intelligent Computing \\ University of Jinan \\ Jinan, China \\ ise_mak@ujn.edu.cn
}

\author{
Xiaohan Ding \\ University of Jinan \\ Shandong Provincial Key \\ Laboratory of Network Based \\ Intelligent Computing \\ Jinan, China \\ 511685276@qq.com
}

\begin{abstract}
The subscription account based on WeChat public platform is a good solution to the interaction problem between the teacher and students. The teaching aid system was designed and achieved through WeChat public platform, which regarded the WeChat subscription account as the link of resource acquisition and teaching interaction in the "flipped classroom". In this way, both of them could be systemically integrated to exert the action of "flipped classroom" indeed, improve the teaching efficiency and promote the reform of teaching practice.
\end{abstract}

Keywords-Teaching Aid System; WeChat; flipped classroom;Java EE

\section{INTRODUCTION}

WeChat public platform is the new functional module added by Tencent, on which individuals and enterprises can create their own public accounts of WeChat and thus realize the all-round communication with the specific group in words, images and voices. The ratio of college students who improve the efficiency of learning and participate in the class has been the hot topic. It is topic worthy to be studied that how to regulate the classroom atmosphere and strengthen the interaction between the teacher and students. WeChat subscription account was employed in this study to design and implement the micro classroom system, which could realize the functions of classroom interaction, query of teaching resources, class exercise and assignment. The real-time capability and participation of social network were introduced in the class, leading to the promising prospect of application. The flipped classroom has been the popular classroom teaching mode in recent years, which realizes the transition from the knowledge inculcation to the ability training to the certain extent in the college classroom. To be specific, the knowledge learning is undergone class to build the students' ability of autonomous learning; while the methods of discussion, exercise and Q\&A are performed in class to examine and consolidate the learning effect. The integration of WeChat subscription account and flipped classroom is a beneficial attempt for the teaching practice.

\section{RESEARCH STATUS}

The flipped classroom is derived from the western countries with the relatively developed education, which has been widely applied and recognized. In 2007, American teachers of Aaron Sams and Jon Bergmann tried the flipped classroom in the class of chemistry for the first time. In 2012, Khan Academy completely adopted the classroom teaching mode based on the flipped classroom, which had become a hot topic of worldwide concern. In 2014, the flipped classroom was regarded as the education 
innovation that would significantly affect the world in NMC Horizon Report: 2014 Higher Education Edition.

WeChat subscription account refers to the platform provided by Tencent, which is the new media to provide the accessible texts, pictures and voices for the public. At present, WeChat public platform has been widely applied and promoted in the fields of micro official website, micro payment, micro community and micro business. Besides, it has also been gradually applied in the field of education. According to the research of literature with the keywords of "WeChat Classroom" on the educational periodicals at home and abroad, there had been 169 papers by August 2016. Where, most of papers focused on the exploration of teaching mode, the design of classroom teaching and the case study; there were limited papers regarding the integration of WeChat classroom, flipped classroom and project-driven teaching. Based upon the analysis and review of literature, it could be found that the researches on the flipped classroom basically began in 2012 in China, while the researches on WeChat classroom in 2013. There has been no academic researches to analyze the effect of WeChat classroom and flipped classroom on the courses of software development based on the method of project-driven learning.

\section{DESIGN OF FLIPPED CLASSROOM BASED ON WECHAT SUBSCRIPTION ACCOUNT}

\section{A. Design for the Implementation Pattern of WeChat Flipped Classroom}

WeChat classroom contributes to the implementation of flipped classroom. Before class, according to the content query and push notification on WeChat classroom, students can actively learn the knowledge and skills required by the flipped classroom. Of course, the teacher can push the contents that should be studied before class to students at the appropriate time. The records and statistics of students' learning can be performed on the server to provide the reference for the class. In class, WeChat classroom is capable of checking the learning effect, in which the knowledge and skills can be consolidated through the interaction between the teacher and students. After class, WeChat classroom can also set to make the cell phone become the efficient learning tool and implement the flipped classroom indeed. The flow chart of WeChat flipped classroom is shown in Fig.1.

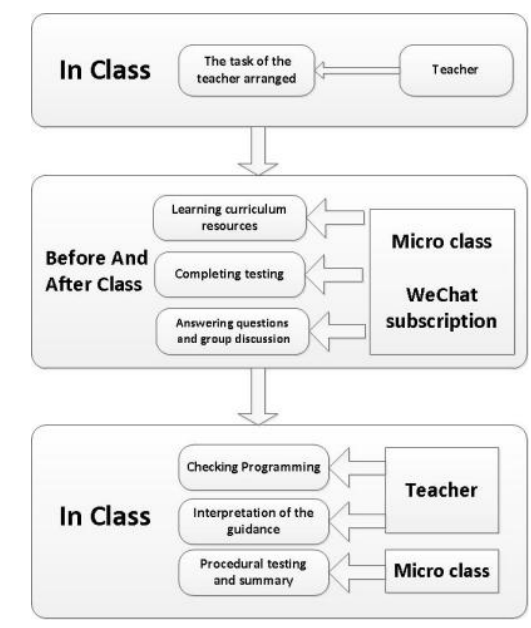

Fig.1 Flow Chart for Implementation Pattern of WeChat Flipped Classroom

\section{B. Design of WeChat Classroom Software}

(1) Architecture of WeChat Public Platform 
The WeChat public platform is mainly divided into four layers: access layer, logic layer, storage layer and external interface layer. The business logic group includes the functions of synchronous services, message, LBS, avatar and messenger bottle; the basic logic group includes the functions of batch queue, status queue and notification queue; the storage layer includes the functions of account information, personal setting, message index of contact and multimedia message; and the external interface layer includes the interfaces of QQ offline message, Sina blog, Facebook and APNS. Being connected to the network, APP on the cell phone can get information and transfer it to the access layer. Afterwards, the data is transmitted to the logic layer through HTTP link. After the business selected by the user is processed by the queue, the message is fed back to the storage layer and external interface one. The back-end architecture of WeChat is shown in Fig.2:

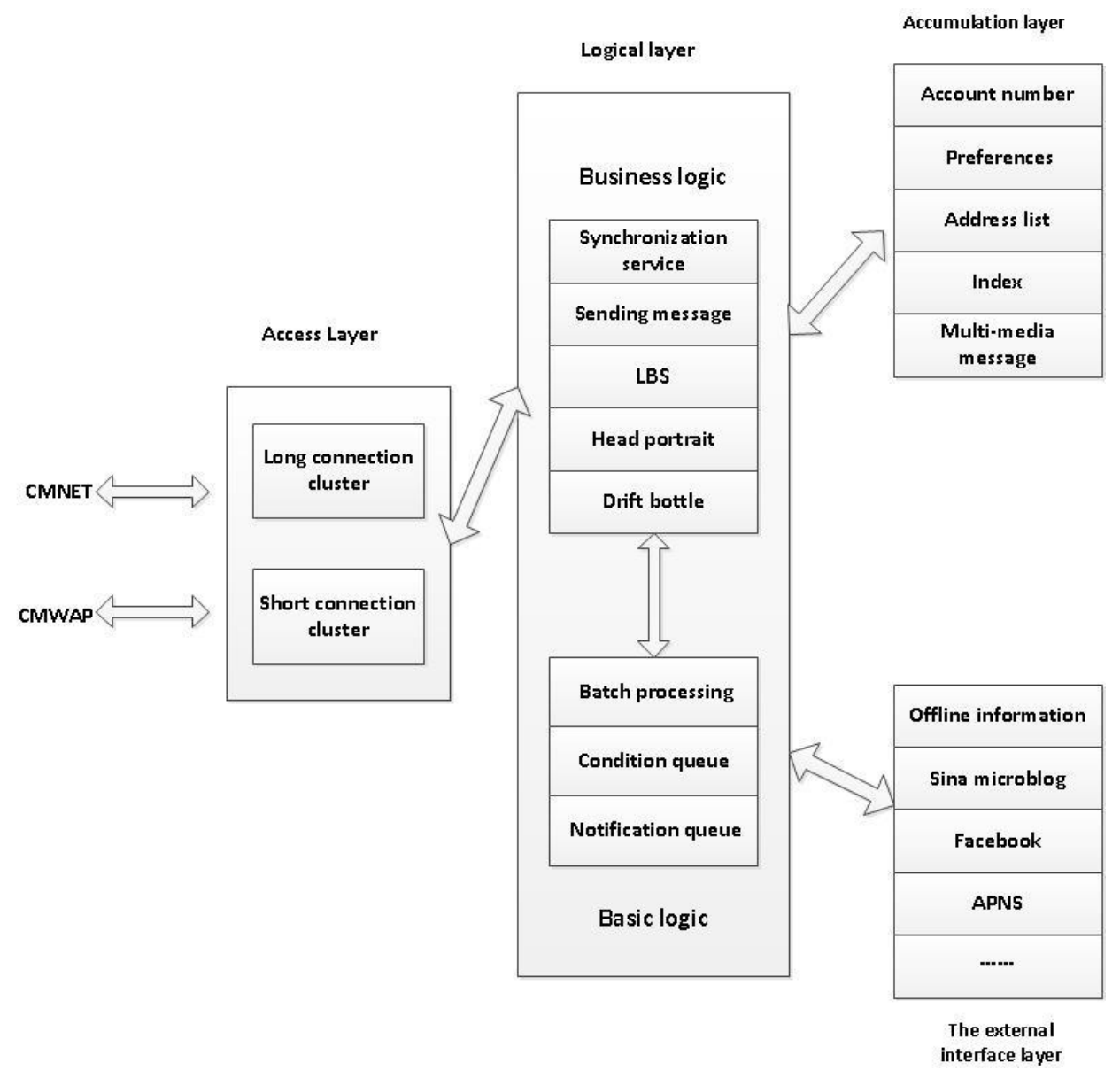

Fig.2 Architecture of WeChat Public Platform

(2) Design for Architecture of WeChat Classroom

WeChat classroom that is based on WeChat subscription account allows the users (student and teacher) to request the resource access through the subscription account of WeChat. As long as such request is received, it would be forwarded by WeChat server to the application server. After the processing in the application server, the related information will be fed back to WeChat server, then the response to the users. The architecture of WeChat classroom is shown in Fig.3: 


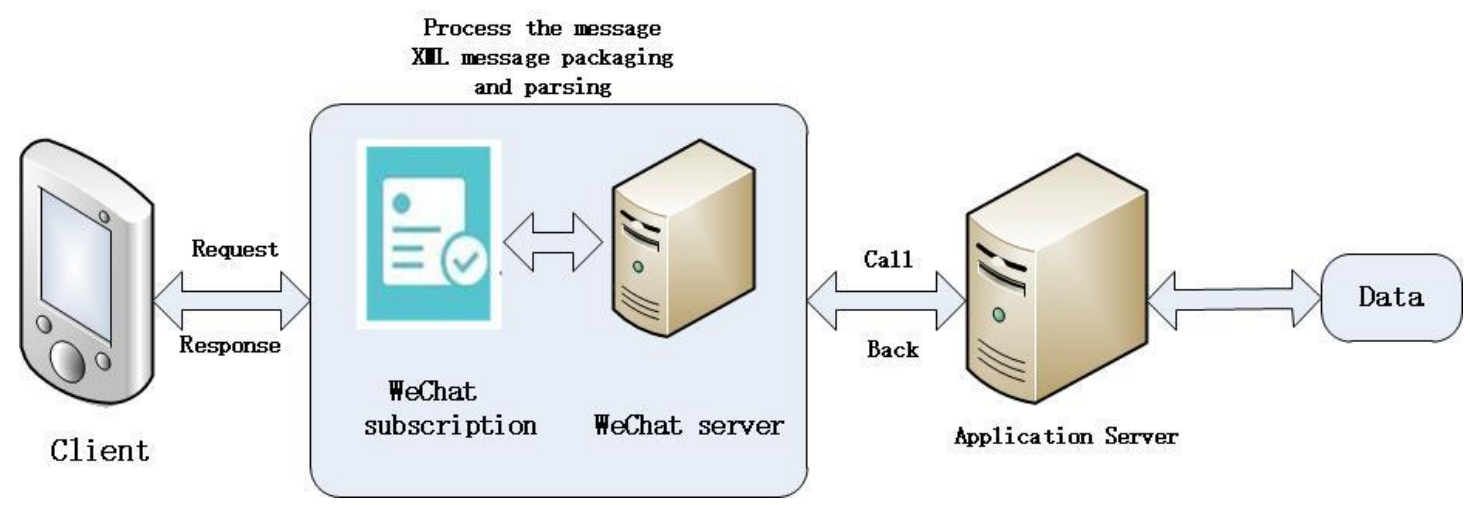

Fig.3 Overall Architecture of WeChat Classroom

(3) Design for Functions of WeChat Classroom

Being implemented on the mobile client, the subscription account is used for the teaching and then it should be connected to the database of the school to get the student ID. The functions of WeChat classroom can be divided into three parts, namely the student, teacher and system. The student's WeChat client includes the functions of binding, check-in, view of teaching resource, homework and class exercises. The teacher's mobile client includes the functions of binding, setting of check-in time, homework setting, assignment of class exercises and score statistics. The system's management client includes the functions of course adding, import of student list who select the course, push notification and deletion. After following the subscription account, the system's management client then has the functions of course adding, import of student list who select the course, deletion and push notification; the teacher's mobile client has the functions of binding, setting of check-in time, homework setting, assignment of class exercises and score statistics; and the student's client has the functions of binding, check-in, view of teaching resource, homework and class exercises. The specific structural diagram of functions is shown in Fig.4:

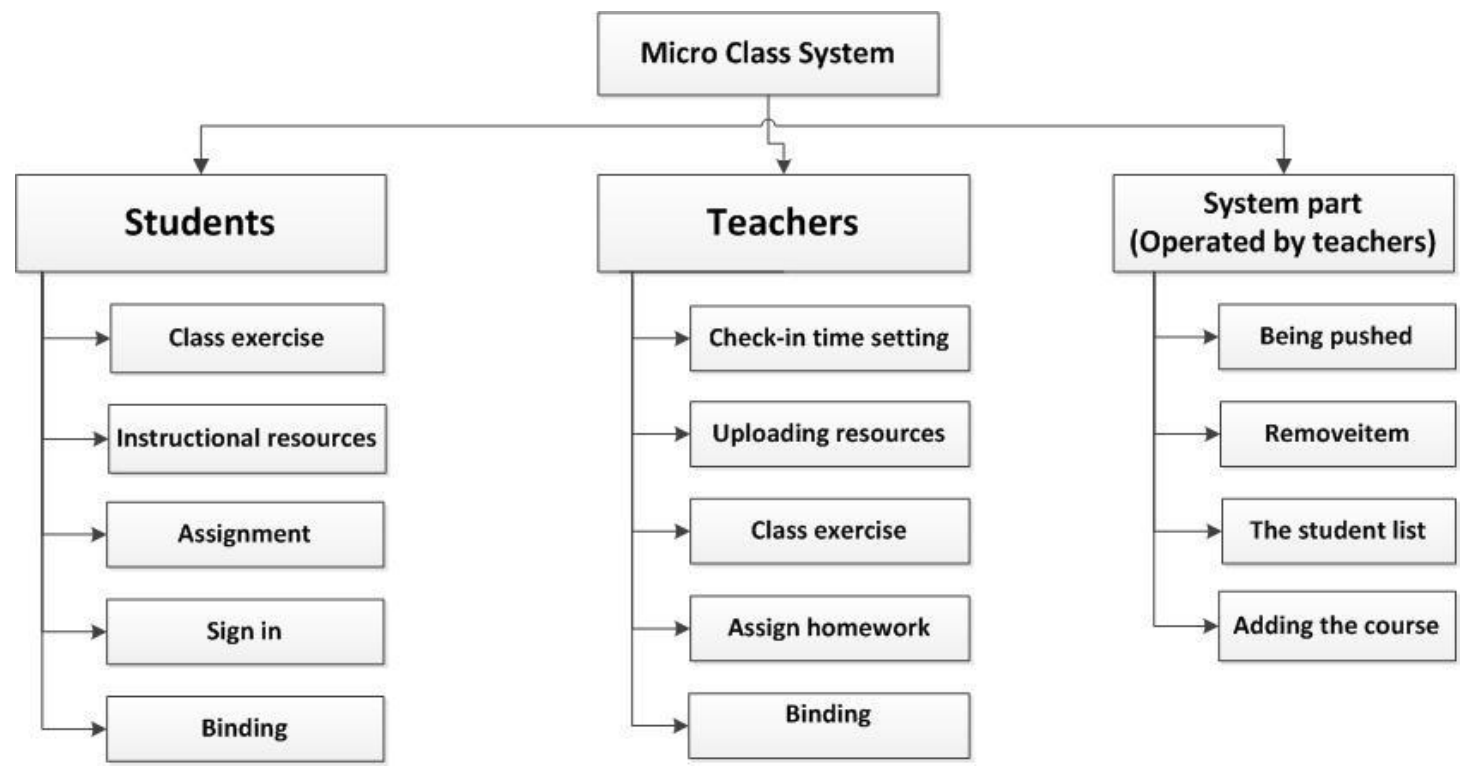

Fig.4 Design for Functions of WeChat Classroom

(4) Implementation and Application Effect of WeChat Classroom 
This method was used in the course of Mobile Internet Development Technology (Android) for the major of Network Engineering 2013 for the first time. It had been explored and improved in the courses of JavaEE-based Advanced Programming, JSP Application Design and Vitality and Innovation of Open Source Project 2.0.

The interactive communication between the students and teacher can be implemented in such system. The student's client has the functions of binding, check-in, homework, view of teaching resource, and class exercises. The teacher's mobile client has the functions of binding, homework setting, statistics of class exercises, upload of resources and setting of check-in time. The system's client that is operated by the teacher has the functions of course adding, import of list of class-skipping students, deletion and push notification. Accordingly, the interaction between the teacher and students can be realized in class and after class. The implementation and operation of system can basically guarantee the teaching effect of flipped classroom, on which students can easily get the homework after class and related resources to get prepared for the autonomous learning. Based on the exercises of WeChat classroom in class, as well as the project-driven teaching method, it is capable to consolidate the knowledge and skills that students should grasp and train the practical ability of students. Besides, it is also convenient for students to go over the course after class. After the implementation for over two years, it has the good effect and the student's evaluation of teaching has been significantly improved.

\section{CONCLUSION}

Presently, the development of network technology provides the good platform and opportunity for the implementation of flipped classroom. The integration of WeChat subscription account and flipped classroom contributes to the deepened reform of software courses basically. The promotion of such mode in the software courses cannot only promote students' learning interest and foster students' ability of autonomous learning, but also realize the student-centralized pattern, fully exert the role of the teacher's guidance, and enhance the student's participation. Accordingly, the teaching pattern is then transited from the traditional "knowledge inculcation" to the "training of ability and quality", from the "teaching" to the "learning", which will be more beneficial for students to cultivate the ability of autonomous learning, the ability of finding and solving the problem, the ability of comprehensively applying the knowledge and technology, and the team consciousness of coordination and distribution of responsibilities.

\section{ACKNOWLEDGEMENT}

This research was financially supported by the university of Jinan Teaching Research Projects Key Projects (JZ1421、JZ1324).

\section{REFERENCES}

[1] Wenliang He, Amanda Holton, George Farkas, Mark Warschauer. The effects of flipped instruction on out-of-class study time, exam performance, and student perceptions[J]. Learning and Instruction, 2016,45(10):61-71.

[2] Yungwei Hao, Kathryn S. Lee. Teaching in flipped classrooms: Exploring pre-service teachers' concerns[J]. Computers in Human Behavior, 2016,57(4):250-260.

[3] Karyn I. Cotta, Samit Shah, Michaela M. Almgren, Lilia Z. Macías-Moriarity, Vicky Mody. Effectiveness of flipped classroom instructional model in teaching pharmaceutical calculations[J]. Currents in Pharmacy Teaching and Learning, 2016,8(5):646-653.

[4] Da Liu. The Reform and Innovation of English Course: A Coherent Whole of MOOC, Flipped Classroom and ESP[J]. Procedia - Social and Behavioral Sciences, 2016,232(8):280-286.

[5] Wei Z.The Analysis of Mobile Internet Impacts on Electronic Commerce System Construction [C]. Paris: Published by Atlantis Press,2013.10:237-242. 